\title{
Using Graphene-powder-based Thermal Interface Material for High Lumen LED Array Chip: An Experimental Study of Heat Dissipation
}

\author{
Chih-Neng Hsu, ${ }^{1 *}$ Chun-Chih Chen, ${ }^{1}$ Chen-Hui Chang, ${ }^{1}$ and Cheng-Chi Wang ${ }^{2}$ \\ ${ }^{1}$ Department of Refrigeration, Air Conditioning and Energy Engineering, \\ National Chin-Yi University of Technology, \\ No. 57, Sec. 2, Zhongshan Rd., Taiping Dist., Taichung 41170, Taiwan, R.O.C. \\ ${ }^{2}$ Graduate Institute of Precision Manufacturing, National Chin-Yi University of Technology, \\ No. 57, Sec. 2, Zhongshan Rd., Taiping Dist., Taichung 41170, Taiwan, R.O.C.
}

(Received July 27, 2020; accepted December 1, 2020)

Keywords: graphene powder, graphene thermal grease, heat dissipation, COB array LED

An LED is solid-state lighting with low environmental impact and green technology. It has the advantages of high luminance, long life, structural strength, and short reaction time. With the continuous improvement in luminous efficiency, the heat energy accumulates rapidly, resulting in a chip-on-board $(\mathrm{COB})$ array LED contact surface that easily exceeds the specification temperature $T_{j}$ and exhibits a sharp drop in light attenuation. Therefore, we blended graphene powder materials and silicone oil to develop excellent graphene grease (10, 15 , and $20 \mathrm{wt} \%$ ) as a contact surface interface medium material with high thermal conductivity, enabling the high-brightness COB array LED to maintain a stable and excellent heat transfer performance. The mixing concentration percentage of the thermally conductive grease is an important influential parameter. Forced convection airflow speeds of $0.5,1.0,1.5,2.0,2.5$, and $3.0 \mathrm{~m} / \mathrm{s}$ are used to simulate the coolant flow rate. The qualitative and quantitative experimental verifications, discussion, the analysis of temperature changes, and flow visualization using a thermal imager flow field are carried out. The contact surface interface medium material with $15 \mathrm{wt} \%$ graphene grease has a relatively good thermal conductivity, but increasing or decreasing the graphene grease concentration causes no clear improvement in thermal conductivity. From the results of forced convection flow visualization, we observed that the airflow speed increases, the thermal boundary layer gradually becomes thinner, and the heat recirculation zone gradually dissipates, which improves the heat transfer effect. In the process of forced convection experiment, we have used the thermocouple temperature $\left(T_{\text {case }}, T_{f}\right.$, and $\left.T_{a}\right)$ sensor and the rotating frequency sensor of axial fan control airflow speed, and a Pitot tube for differential pressure sensing is used to measure and transmit data to a recorder.

\section{Introduction}

The lamp is a lighting device and has been the symbol of man-made light since ancient times. With the evolution of technology from the 18th century to the 21 st century, inventors *Corresponding author: e-mail: cnhsu@ncut.edu.tw https://doi.org/10.18494/SAM.2020.3137 
have been working hard to change the brightness of man-made lighting devices. ${ }^{(1)}$ The lamp will push lighting toward a new generation of technological development and transformation. There are many types of light in this bright era, such as indoor, outdoor, projection, exploration, and guidance lights. Fuel lighting will be replaced, improving the safety of day and night lighting. The energy consumption of lighting equipment cannot be ignored, so the old types of light lamp that consume much energy (incandescent, fluorescent, halogen, mercury, xenon, and sodium lamps) will ultimately become obsolete. ${ }^{(2)}$ LEDs have high brightness, long life, high structural strength, large light volume, short reaction time, no mercury vapor, and other advantages for sustainable development and energy saving. Silicon carbide, used in solid-state lighting, is a group III-V semiconductor material ${ }^{(3-5)}$ that needs a good thermal conductivity medium material to improve the heat transfer effect. Therefore, a solid is generally used as the interface contact heat dissipation material. ${ }^{(6,7)}$ Since the heat transfer is still limited, some special high-thermal-conductivity materials or high cooling methods ${ }^{(8-12)}$ should be used to enhance the efficiency. Therefore, some technologies, such as heat pipes, vapor chambers, refrigeration, air conditioning, sprays, phase materials, thermal pads, thermoelectric coolers, and microchannels, ${ }^{(13-24)}$ for assisting the cooling element to achieve heat dissipation and a special new technology to increase performance have been developed. Lee et al. ${ }^{(25)}$ proposed that graphene nanosheets of uniform shape may be incorporated into the silicon sealant for LEDs by solvent exchange. Graphene embedded in the silicone sealant has a multifunctional role in improving the performance of LEDs. The presence of graphene leads to effective heat dissipation, which inhibits the introduction of moisture and harmful gases from the outside, improving the mechanical properties. Then, the performance of COB array LED can be obtained by thermocouple temperature sensing, flow velocity sensing, voltage and current transmission, flow visualization image sensing photography, environmental control room temperature and relative humidity sensing, and so forth.

\section{Principle of High-luminance Chip on Board Array LED}

The chip-on-board (COB) array LED is a multichip InGaN/GaN element package, as shown in Fig. 1. The principle of this lighting package is the same as that of the die silicon chip package, because electric energy is directly converted to light and heat energy when a forward

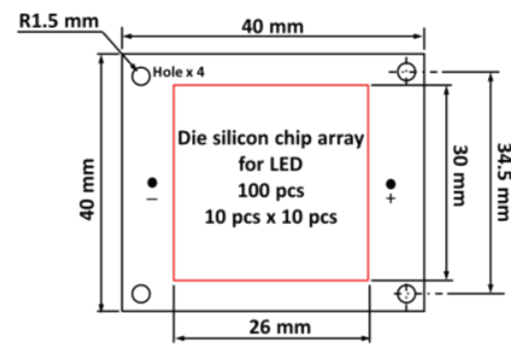

(a)

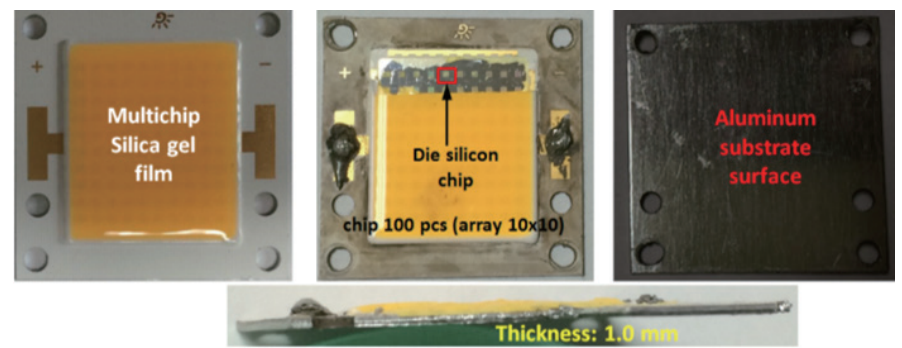

(b)

Fig. 1. (Color online) High-luminance COB array LED for 50-100 W. 
bias voltage is applied to the positive and negative ends of the semiconductor. When current flows, electrons are combined with the electromotive force, and the excess energy is released in the form of photons. Depending on the material used, the energy gap of photons can generate light of blue wavelengths, and the light particles passing through the phosphor can produce white light illumination, as shown in Fig. . $^{(5)}$

\section{Graphene Powder and Graphene Thermal Grease}

To achieve a better heat dissipation mode of the multichip COB LED, graphene powder (sheet material) is prepared using a newly formulated graphene material with high thermal conductivity. It is combined with methyl phenyl silicone oil as the high-temperature oil [molecular formula: $\left(\mathrm{C}_{7} \mathrm{H}_{8} \mathrm{OSi}\right) n$, density: $1.102 \mathrm{~g} / \mathrm{mL}$ at $25{ }^{\circ} \mathrm{C}$ (lit.), vapor density: $>1$ (vs air), and vapor pressure: $\left.<5 \mathrm{~mm} \mathrm{Hg}\left(25^{\circ} \mathrm{C}\right)\right]$ to prepare the graphene thermal grease used as the interface conductive material in the experiment, as shown in Fig. 3. Graphene thermal grease with different concentrations of graphene powder (10, 15, and $20 \mathrm{wt} \%)$ is prepared and evenly applied to the interface between the LED substrate and the heat dissipation fin. Then, a type $\mathrm{T}$ thermocouple wire is pressed onto the interface, and the LED is locked with the heat sink

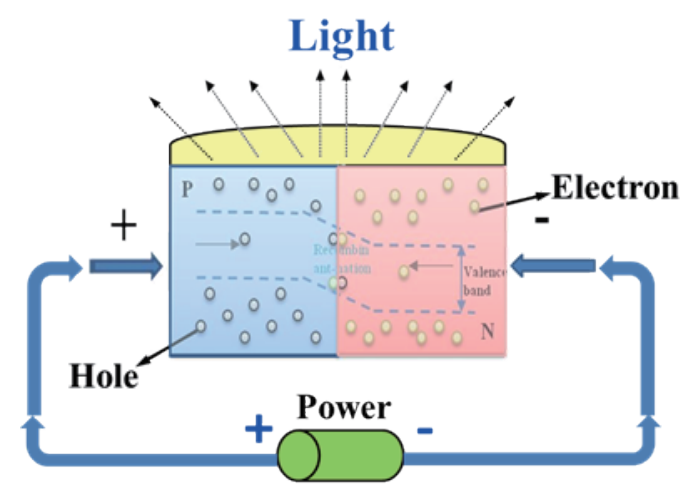

Fig. 2. (Color online) Principle of LED lighting. ${ }^{(5)}$

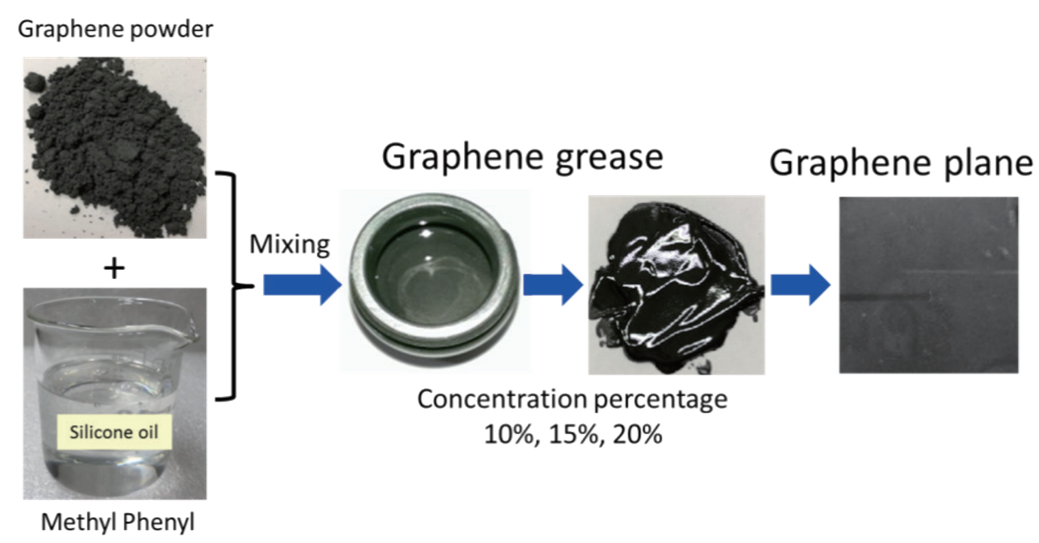

Fig. 3. (Color online) Graphene powder is made into thermally conductive graphene grease. 
fin using a torque wrench. The test material is an aluminum extrusion heat sink material, AL 6069 [heat conductivity: $200 \mathrm{~W} / \mathrm{m} \cdot \mathrm{K}$; aluminum extrusion: 9 fins of 64 or $125 \mathrm{~mm}$ length (L), $125 \mathrm{~mm}$ width (W), and $72 \mathrm{~mm}$ height (H)], as shown in Fig. 4, and the aluminum forging heat sink material is AL 1070 (heat conductivity: $229 \mathrm{~W} / \mathrm{m} \cdot \mathrm{K}$; aluminum forging: 232 fins of 64 or $125 \mathrm{~mm} \mathrm{~L}, 125 \mathrm{~mm} \mathrm{~W}$, and $72 \mathrm{~mm} \mathrm{H}$ ), as shown in Fig. 5 .

\section{Experimental Setup}

\subsection{Flowchart of experimental research}

In this work, the heat conduction from a COB LED to a fin heat sink and the convection of air are studied. The flowchart of COB LED experimental measurement under natural and forced convection study conditions is shown in Fig. 6.
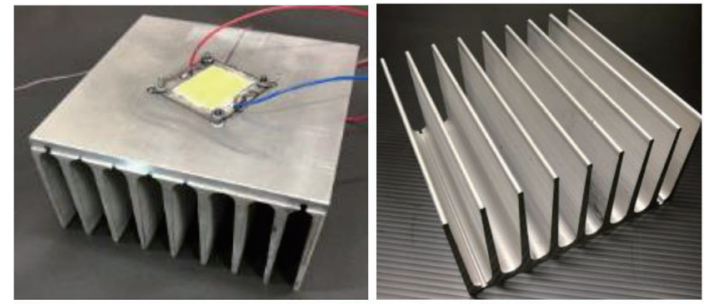

Fig. 4. (Color online) Aluminum extrusion heat sink material: AL 6069.

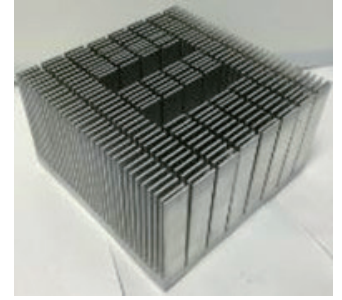

Fig. 5. (Color online) Aluminum forging heat sink material: AL 1070.

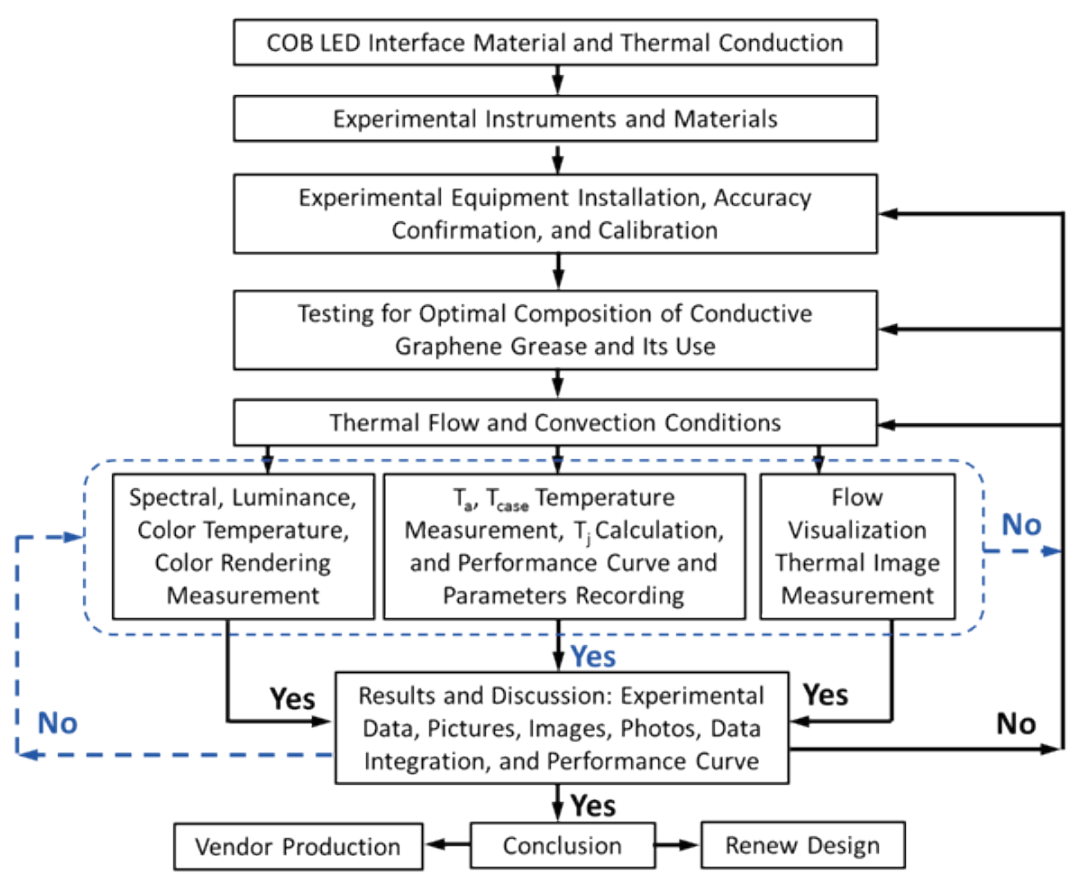

Fig. 6. (Color online) Flowchart of this research. 


\subsection{Experimental procedure}

1. Use an anemometer and a Pitot tube in the test duct to measure the control values of the frequency and wind speed of the aspirating subsonic wind tunnel, and compare them with each other to ensure the correct wind speed.

2. Apply the heat-conduction graphene grease with the best heat dissipation effect to the interface between the COB LED substrate and the heat sink module, connect the type T thermocouple, and attach the torque plate.

3. Place the COB LED module in the test flow channel, connect two type $T$ thermocouple lines to the COB LED for contact surface temperature and cooling fin surface temperature measurement, and connect one end of two type T thermocouple lines to the GL840 data recorder for real-time temperature monitoring. The recording frequency is once every $2 \mathrm{~s}$.

4. Connect the positive and negative ends of the COB LED to the power supply, adjust the test wattage to $100 \mathrm{~W}$, and monitor the voltage and current constantly to maintain a fixed input power, always paying attention to $T_{\text {case }}$ to avoid burn out.

5. At the beginning of the experiment, turn on the COB LED and adjust the wattage to $100 \mathrm{~W}$. Measure the changes in $T_{\text {case }}, T_{f}$, and $T_{a}$ under different airflow speeds $(0.5,1.0,1.5,2.0,2.5$, and $3.0 \mathrm{~m} / \mathrm{s}$ ). Calculate $T_{j}$ and draw the performance curve. The experimental recording time and temperature reach the steady state.

6. After the temperature reaches the steady state, use the infrared thermal imager to capture the temperature distributions of the COB LED and cooling heat sink module under different airflow speeds.

7. Install the digital camera and laser light generator equipment in their correct positions, turn on the laser light generator after operating the infrared thermal imager, and introduce smoke into the airflow channel to observe the change in heat flow visualized near the COB LED heat sink module and the effect at the thermal boundary with the heat flow field state.

\subsection{Experimental equipment}

The thermal experiment and flow visualization of forced convection for the test flow channel of $800 \mathrm{~mm} \mathrm{~L} \times 200 \mathrm{~mm} \mathrm{~W} \times 200 \mathrm{~mm} \mathrm{H}$ is shown in Fig. 7. The equipment used in the experimental measurement is the laser (output power: $300 \mathrm{~mW}$, laser beam: $\psi 2.5 \mathrm{~mm}$, wavelength: $532 \mathrm{~nm}$ for green light, and output stability: $\leq \pm 5 \%$ ), the camera recorder with flow visualization (full HD $1080 \mathrm{P}, 24.72 \times 10^{6}$ pixels, and 1/8000 to $30 \mathrm{~s}$ speed), the multirange DC power supply (voltage: 0 to $80 \mathrm{~V}$, current: 0 to $40.5 \mathrm{~A}$, and power output: $1080 \mathrm{~W}$ ), the data acquisition system (GL-840M, 20 channels, and $20 \mathrm{mV}$ to $100 \mathrm{~V}$ ), the thermocouple (Type T, temperature range: -270 to $370{ }^{\circ} \mathrm{C}$, and accuracy standard: $\pm 1.0{ }^{\circ} \mathrm{C}$ or $\pm 0.75 \%$ ), the infrared thermal imager (measuring range: -20 to $250{ }^{\circ} \mathrm{C}$, thermal image pixels: $80 \times 60$ pixels, and accuracy: $\pm 2 \%$ or $\pm 2{ }^{\circ} \mathrm{C}$ ), and the digital light meter spectrometer (spectral wavelength range: 360 to $750 \mathrm{~nm}$, resolution: $12 \mathrm{~nm}$, measurement time: 8 to $1000 \mathrm{~ms}$, illumination: 70 to 70000 lux, CIE 1931 and CIE 1976, relative color temperature accuracy: $\pm 2 \%$, and illumination accuracy: $\pm 5 \%$ ). The convection environmental control room was used to test the LED temperature, as shown in Fig. 8. 


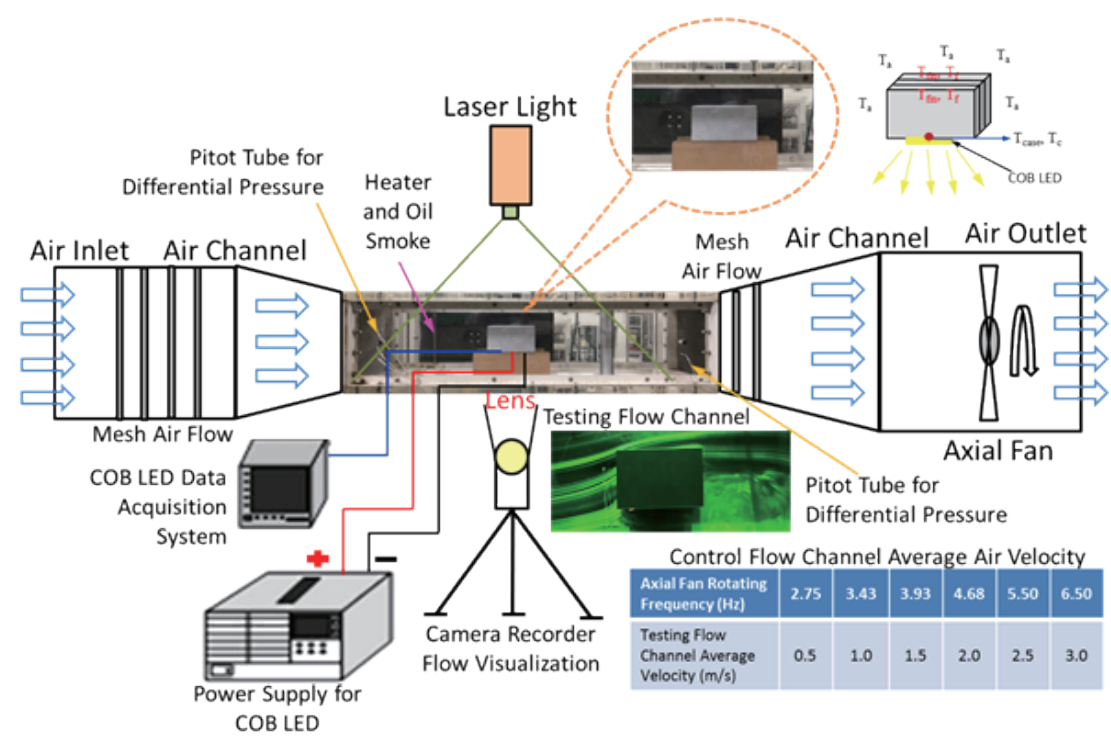

Fig. 7. (Color online) Thermal experiment and flow visualization of forced convection.
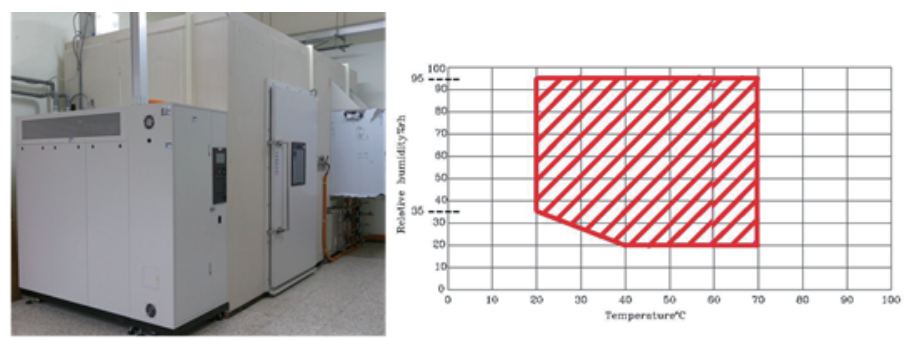

Specifications:

- Temperature range: $-20-+70{ }^{\circ} \mathrm{C}$.

- Relative humidity: $20-95 \% \mathrm{RH}$.

- Stability: $\pm 0.2^{\circ} \mathrm{C}$ and $\pm 2.5 \% \mathrm{RH}$.

- Distribution uniformity: $\pm 1^{\circ} \mathrm{C}, \pm 5 \% \mathrm{RH}$ (non-loading)

- Heating time: $+20-+70^{\circ} \mathrm{C}$ (about 30 min @ non-loading).

- Cooling time: $+20--20^{\circ} \mathrm{C}$ (about $60 \mathrm{~min} @$ non-loading).

Fig. 8. (Color online) Environmental control room for COB LED temperature verification.

\section{Results and Discussion}

\subsection{Forced convection performance evaluation in environmental control room}

Forced convection air cooling is used to test the change in $T_{\text {case }}$ under different airflow speeds. A standard wind tunnel is used to control the forced air convection speed to determine the optimal air cooling speed for dealing with the hot spots of heat accumulation on the multichip COB LED. The forced convection is applied in the wind tunnel channel test and device and frame experiments. Graphene grease has good thermal conductivity and reliability. The COB LED is tested in a forced convection wind tunnel with an ambient temperature of $25{ }^{\circ} \mathrm{C}$ for a test time of $3000-3600 \mathrm{~s}$. $T_{\text {case }}$ values are 57,56 , and $55^{\circ} \mathrm{C}$ at airflow velocities 
of $1.5-1.7,2.0$, and $3.0 \mathrm{~m} / \mathrm{s}$, respectively. When the airflow speed is close to $1.7 \mathrm{~m} / \mathrm{s}$, the heat dissipation of the COB LED tends to be stable, and increasing the airflow speed has little effect on heat dissipation. Therefore, the forced convection wind speed of $1.7 \mathrm{~m} / \mathrm{s}$ is selected as the benchmark of forced convection airflow speed. Because natural convection cooling does not solve the hot spot problem of the $100 \mathrm{~W}$ COB LED, forced convection cooling is promising as the heat transfer method. The concentration of graphene powder in the graphene grease used as the interface thermal conduction medium material for forced convection is $15 \%$. The aluminum extrusion and cold forging heat sinks are configured on the basis of heat capacity shown in Fig. 9(a).

In the experiment, after $T_{\text {case }}$ becomes stable, the temperature distribution of the heat sink module under different airflow speeds, the observation of the heat flow field, and the effect of

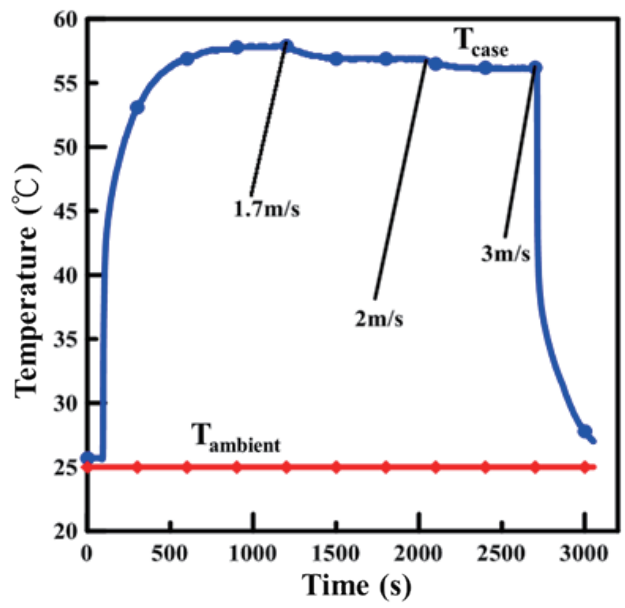

(a)

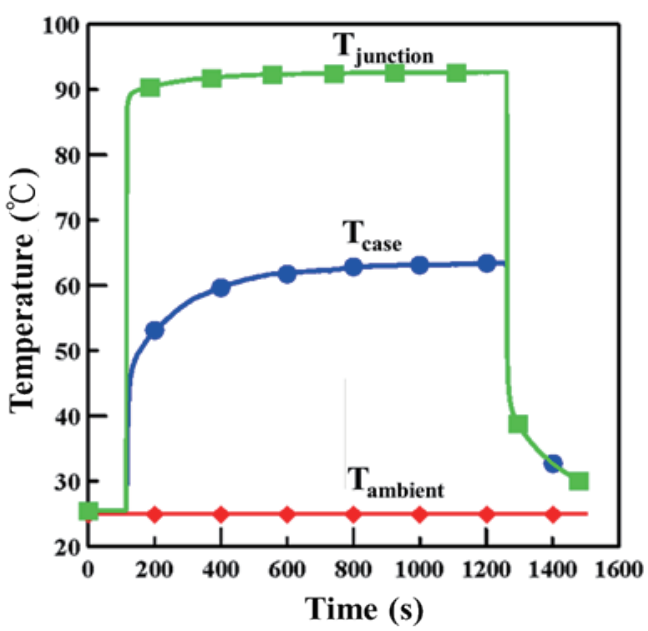

(c)

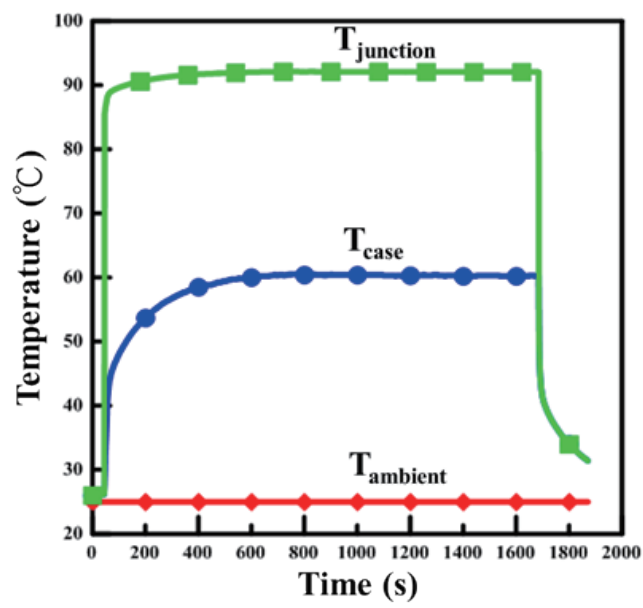

(b)

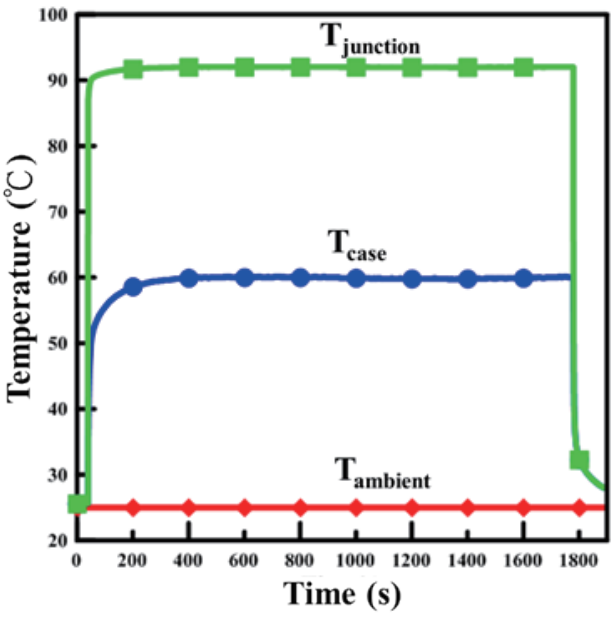

(d)

Fig. 9. (Color online) (a). Results of COB LED heat dissipation airflow speed testing. (b) Results of temperature of $100 \mathrm{~W}$ COB LED interface with graphene grease. (c) Results of temperature of $100 \mathrm{~W}$ COB LED interface with graphene grease and surface of aluminum extrusion heat sink sprayed with liquid graphene. (d) Results of temperature of $100 \mathrm{~W}$ COB LED and cold forging aluminum heat sink module interface with graphene grease. 
the thermal boundary layer on the cooling module are examined. It is found that $T_{a}$ reaches $32.6{ }^{\circ} \mathrm{C}$ and the calculated junction temperature $T_{j}$ of the chip reaches $84.4{ }^{\circ} \mathrm{C}$ when the graphene concentration is $10 \%$. $T_{a}$ reaches $32{ }^{\circ} \mathrm{C}$ and the calculated $T_{j}$ reaches $82.7^{\circ} \mathrm{C}$ when the graphene concentration is $15 \%$. $T_{a}$ reaches $32.9{ }^{\circ} \mathrm{C}$ and the calculated $T_{j}$ reaches $84.44{ }^{\circ} \mathrm{C}$ when the graphene concentration is $20 \%$. The empirical formula used in this study is modified as

$$
T_{j, \text { cal }}=T_{\text {case }}+W_{\text {loss }} \times\left(\frac{T_{j, \text { spec }}-T_{\text {case }}-T_{\text {ambient }}}{W_{\text {spec }}}\right) \times\left(\frac{W_{\text {act }}}{W_{\text {spec }}}\right) .
$$

\subsection{Aluminum extrusion heat sink module}

The interface between the $100 \mathrm{~W}$ COB LED alumina substrate and the aluminum extrusion heat sink is made conductive by applying self-developed graphene thermal grease in forced convection $(1.5-1.7 \mathrm{~m} / \mathrm{s})$. COB LED $T_{\text {case }}$ is $57-59{ }^{\circ} \mathrm{C}$, which is lower than the specification temperature of $75{ }^{\circ} \mathrm{C}$ for the COB LED, and COB LED $T_{j}$ is $90-92{ }^{\circ} \mathrm{C}$, which is lower than the specification temperature of $125^{\circ} \mathrm{C}$ for the COB LED, as shown in Fig. 9(b). The graphene thermal grease is a suitable thermally conductive (grease) interface material that will not be oxidized or affected by the environment. The self-developed graphene grease is used at the interface between the $100 \mathrm{~W}$ COB LED alumina substrate and the aluminum extrusion heat sink, and liquid graphene is sprayed on the surface of the aluminum extrusion heat sink module to induce the forced convection $(1.5-1.7 \mathrm{~m} / \mathrm{s})$ mode. After 1,200 $\mathrm{s}$ of forced convection, COB LED $T_{\text {case }}$ reaches $64{ }^{\circ} \mathrm{C}$, and the temperature continues to rise below the specification temperature of $75{ }^{\circ} \mathrm{C}$ for the COB LED. COB LED $T_{j}$ reaches $92{ }^{\circ} \mathrm{C}$, which is lower than the specification temperature of $125^{\circ} \mathrm{C}$ for the COB LED. Overall, it is $2{ }^{\circ} \mathrm{C}$ higher than the temperature in the case without the spraying of liquid graphene on the surface of the aluminum extruded heat sink. It shows that graphene is a poor material for the surface coating of the heat sink module surface. It causes an undesirable heat transfer effect of black-body thermal-radiation-absorbing heat energy, as shown in Fig. 9(c).

\subsection{Cold forging aluminum heat sink module}

When the $100 \mathrm{~W}$ COB LED of the forging heat sink module is activated (the interface has self-developed graphene grease), the COB LED temperature rises faster and becomes more stable than that of the aluminum extrusion heat sink module. The voltage and current of the COB LED can be accurately controlled within the set range so that $T_{\text {case }}$ of the COB LED can be controlled very stably between 59 and $61{ }^{\circ} \mathrm{C}$, which is lower than the specification temperature of $75{ }^{\circ} \mathrm{C}$ for the COB LED. $T_{j}$ is between 90 and $91{ }^{\circ} \mathrm{C}$, which is lower than the specification temperature of $125^{\circ} \mathrm{C}$ for the COB LED. However, compared with the cooling temperature of the aluminum extrusion heat sink module, the stable temperatures of the two materials are close to each other, and there is no significant difference between them. The self-developed graphene grease can help the heat transfer at the interface and can cool the convection airflow $(1.7 \mathrm{~m} / \mathrm{s})$, as shown in Fig. 9(d). 


\subsection{Change in COB LED interface temperature}

The change in COB LED interface temperature is examined by forced convection testing under the following conditions: $15 \%$ graphene grease at the interface of the $100 \mathrm{~W}$ COB LED, ambient temperature $T_{a}$ of $25^{\circ} \mathrm{C}$, and airflow speeds of $0.5,1.0,1.5,2.0,2.5$, and $3.0 \mathrm{~m} / \mathrm{s}$.

\subsubsection{Airflow speed of $0.5 \mathrm{~m} / \mathrm{s}$}

The COB LED interface temperature $T_{\text {case }}$ is stable from 1600 to $3600 \mathrm{~s}$, and time is measured between 0 and $3600 \mathrm{~s}$ when the convection airflow speed is $0.5 \mathrm{~m} / \mathrm{s}$ from the start of forced convection, as shown in Fig. 10(a). It is found that the interface temperature $T_{\text {case }}$ is $73.38{ }^{\circ} \mathrm{C}$, which is lower than the specification temperature of $75{ }^{\circ} \mathrm{C}$ for the COB LED. The calculated chip junction temperature $T_{j}$ is $94.67{ }^{\circ} \mathrm{C}$, which is lower than the specification temperature of $125^{\circ} \mathrm{C}$ for the COB LED. The heat sink fin module temperature $T_{f}$ is $45.78^{\circ} \mathrm{C}$.

\subsubsection{Airflow speed of $1.0 \mathrm{~m} / \mathrm{s}$}

The COB LED interface temperature $T_{\text {case }}$ is stable from 1200 to $2600 \mathrm{~s}$, and time is measured between 0 and $2600 \mathrm{~s}$ when the convection airflow speed is $1.0 \mathrm{~m} / \mathrm{s}$ from the start of forced convection, as shown in Fig. 10 (b). It is found that $T_{\text {case }}$ is $69.14{ }^{\circ} \mathrm{C}$, which is lower than the specification temperature of $75^{\circ} \mathrm{C}$ for the COB LED. The calculated $T_{j}$ is $93.82{ }^{\circ} \mathrm{C}$, which is lower than the specification temperature of $125^{\circ} \mathrm{C}$ for the COB LED. $T_{f}$ is $42.16^{\circ} \mathrm{C}$.

\subsubsection{Airflow speed of $1.5 \mathrm{~m} / \mathrm{s}$}

The COB LED interface temperature $T_{\text {case }}$ is stable from 1400 to $2400 \mathrm{~s}$, and time is measured between 0 and $2400 \mathrm{~s}$ when the convection airflow speed is $1.5 \mathrm{~m} / \mathrm{s}$ from the start of forced convection, as shown in Fig. 10 (c). It is found that $T_{\text {case }}$ is $66.89^{\circ} \mathrm{C}$, which is lower than the specification temperature of $75^{\circ} \mathrm{C}$ for the COB LED. The calculated $T_{j}$ is $93.37{ }^{\circ} \mathrm{C}$, which is lower than the specification temperature of $125^{\circ} \mathrm{C}$ for the COB LED. $T_{f}$ is $40.23{ }^{\circ} \mathrm{C}$.

\subsubsection{Airflow speed of $2.0 \mathrm{~m} / \mathrm{s}$}

The COB LED interface temperature $T_{\text {case }}$ is stable from 1200 to $2200 \mathrm{~s}$, and time is measured between 0 and $2200 \mathrm{~s}$ when the convection airflow speed is $2.0 \mathrm{~m} / \mathrm{s}$ from the start of forced convection, as shown in Fig. 10 (d). It is found that $T_{\text {case }}$ is $63.85^{\circ} \mathrm{C}$, which is lower than the specification temperature of $75^{\circ} \mathrm{C}$ for the COB LED. The calculated $T_{j}$ is $92.77{ }^{\circ} \mathrm{C}$, which is lower than the specification temperature of $125^{\circ} \mathrm{C}$ for the COB LED. $T_{f}$ is $37.80{ }^{\circ} \mathrm{C}$.

\subsubsection{Airflow speed of $2.5 \mathrm{~m} / \mathrm{s}$}

The COB LED interface temperature $T_{\text {case }}$ is stable from 800 to $2200 \mathrm{~s}$, and time is measured between 0 and $2200 \mathrm{~s}$ when the convection airflow speed is $2.5 \mathrm{~m} / \mathrm{s}$ from the start of 


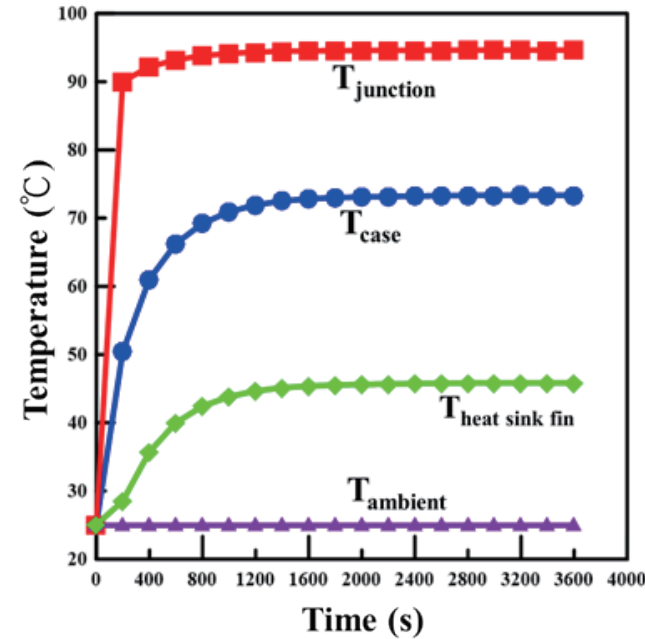

(a)

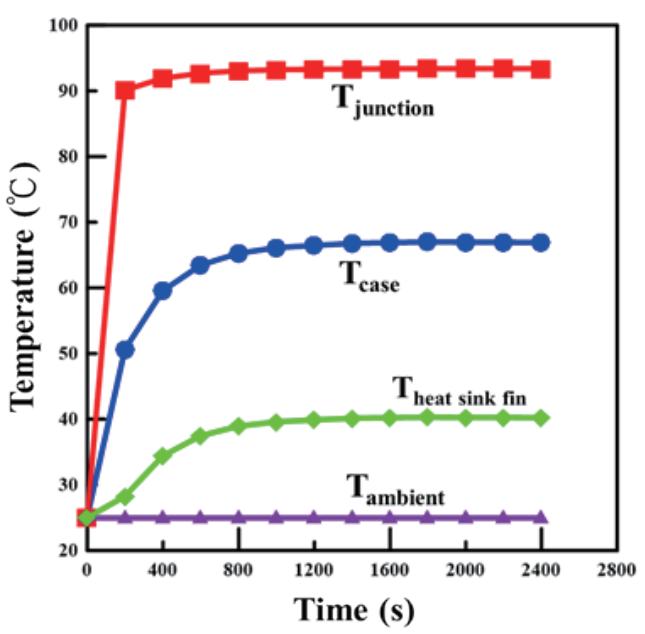

(c)

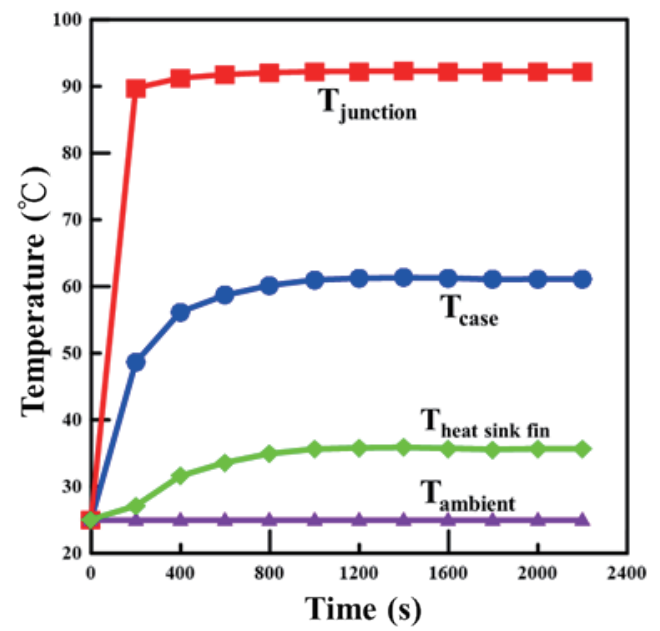

(e)

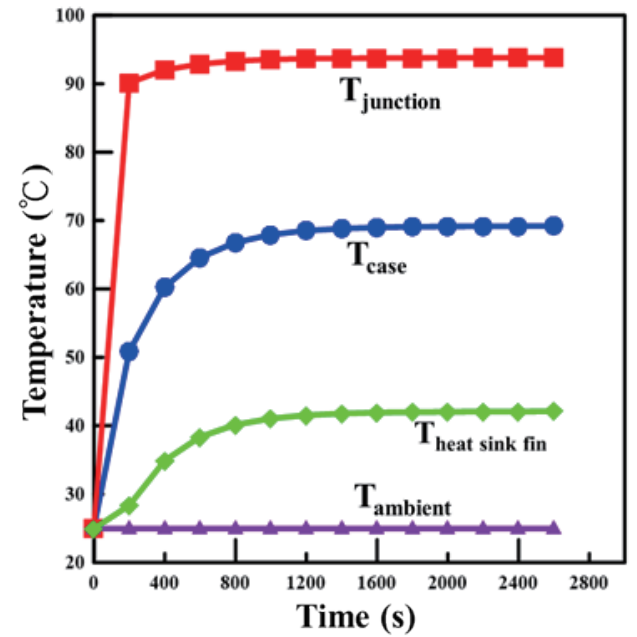

(b)

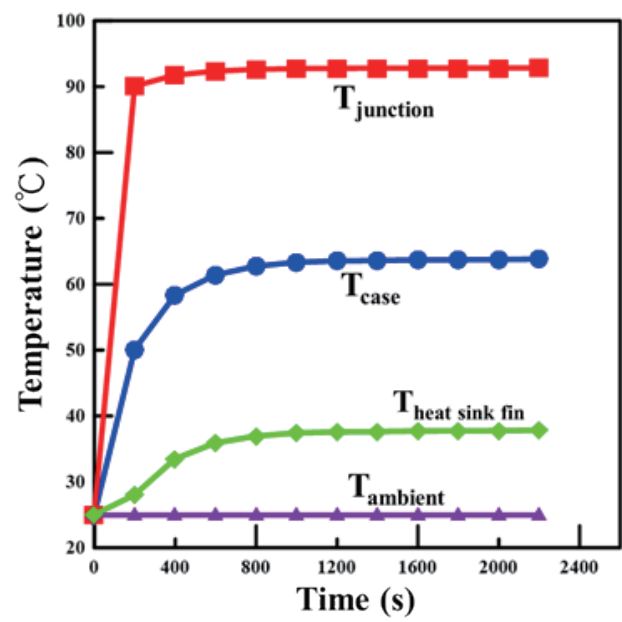

(d)

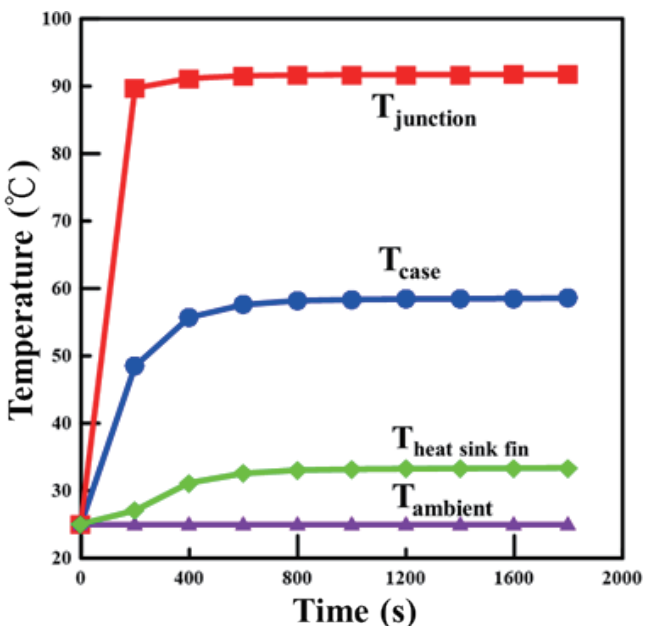

(f)

Fig. 10. (Color online) Time vs measured temperature for difference airflow speed. (a) Airflow speed of $0.5 \mathrm{~m} / \mathrm{s}$. (b) Airflow speed of $1.0 \mathrm{~m} / \mathrm{s}$. (c) Airflow speed of $1.5 \mathrm{~m} / \mathrm{s}$. (d) Airflow speed of $2.0 \mathrm{~m} / \mathrm{s}$. (e) Airflow speed of $2.5 \mathrm{~m} / \mathrm{s}$. (f) Airflow speed of $3.0 \mathrm{~m} / \mathrm{s}$. 
forced convection, as shown in Fig. $10(\mathrm{e})$. It is found that $T_{\text {case }}$ is $61.13{ }^{\circ} \mathrm{C}$, which is lower than the specification temperature of $75{ }^{\circ} \mathrm{C}$ for the COB LED. The calculated $T_{j}$ is $92.22{ }^{\circ} \mathrm{C}$, which is lower than the specification temperature of $125^{\circ} \mathrm{C}$ for the COB LED. $T_{f}$ is $35.61{ }^{\circ} \mathrm{C}$.

\subsubsection{Airflow speed of $3.0 \mathrm{~m} / \mathrm{s}$}

The COB LED interface temperature $T_{\text {case }}$ is stable from 600 to $1800 \mathrm{~s}$, and time is measured between 0 and $1800 \mathrm{~s}$ when the convection airflow speed is $3.0 \mathrm{~m} / \mathrm{s}$ from the start of forced convection, as shown in Fig. 10(f). It is found that $T_{\text {case }}$ is $58.54{ }^{\circ} \mathrm{C}$, which is lower than the specification temperature of $75^{\circ} \mathrm{C}$ for the COB LED. The calculated $T_{j}$ is $91.70{ }^{\circ} \mathrm{C}$, which is lower than the specification temperature of $125^{\circ} \mathrm{C}$ for the COB LED. $T_{f}$ is $33.34{ }^{\circ} \mathrm{C}$.

It can be seen from Fig. 11 that with the gradual increase in airflow speed, $T_{\text {case }}$ and the calculated $T_{j}$ show a gradually decreasing trend, and when the airflow speed increases, the time required for temperature to reach stability gradually decreases: $3600 \mathrm{~s}$ at $0.5 \mathrm{~m} / \mathrm{s}$ and $1800 \mathrm{~s}$ at $3.0 \mathrm{~m} / \mathrm{s}$. The difference in $T_{\text {case }}$ between the cases of 0.5 and $1.0 \mathrm{~m} / \mathrm{s}$ is $4.24{ }^{\circ} \mathrm{C}$ and that between the cases of 2.5 and $3.0 \mathrm{~m} / \mathrm{s}$ is $2.59{ }^{\circ} \mathrm{C}$. After the airflow speed reaches a certain value, the cold air molecules cannot completely remove the heat of the hot air molecules on the material surface, whereby the thermal boundary layer continues to exist, but the energy consumption increases, with the consequent result that heat cannot be removed continuously. Therefore, the optimization of the airflow rate and the combination of the heat sink fin area and rough surface will lead to improved heat transfer. The COB LED device is better than a fluorescent lamp in controlling the power wattage, color temperature, lighting, and color rendering index with energy-saving.

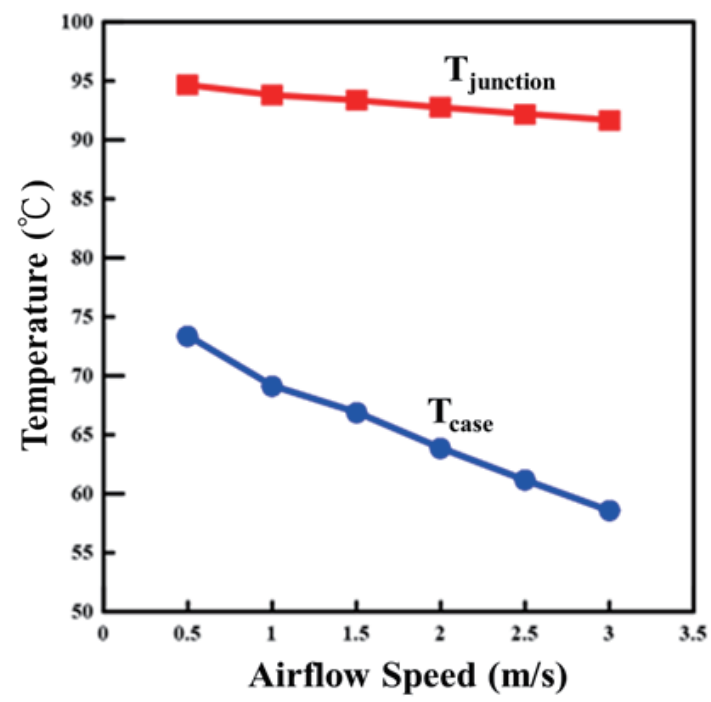

Fig. 11. (Color online) Airflow speed vs temperature. 


\subsection{Flow visualization phenomena under different airflow speeds}

\subsubsection{Airflow speed of $0.5 \mathrm{~m} / \mathrm{s}$}

The results obtained under air convection with the airflow speed of $0.5 \mathrm{~m} / \mathrm{s}$ are shown in Fig. 12(a). When the smoke flows through the cooling module, it can be seen that the flow is disturbed by temperature and thermal buoyancy. The smooth flow field becomes chaotic after the smoke passes through the heat dissipation module, and the thermal buoyancy effect also causes the line of heat flow to drift upward. As shown in Fig. 12(b), it is clear that the heat dissipation module is affected by high temperature, and the surface of the heat sink fin forms a thermal boundary. With higher temperature, the thermal boundary layer is thicker. When the smoke passes between two cooling fins, it is squeezed by the fin spacing and thermal boundary layer, and the closer the smoke is to the bottom of the heat dissipation module, the higher the temperature, the thicker the thermal boundary layer, and the greater the impact of heat dissipation, resulting in higher velocity upstream and lower velocity downstream. The downstream smoke forms a vortex retention area, and hot air flows back to the bottom of the cooling module, which reduces the heat dissipation capacity.

\subsubsection{Airflow speed of $1.0 \mathrm{~m} / \mathrm{s}$}

The results obtained under air convection with the airflow speed of $1.0 \mathrm{~m} / \mathrm{s}$ are shown in Fig. 13(a). Compared with the case of airflow speed of $0.5 \mathrm{~m} / \mathrm{s}$, the effect of thermal buoyancy

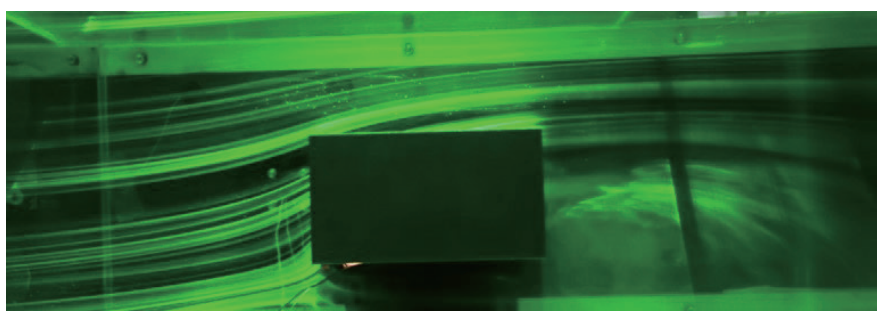

(a)

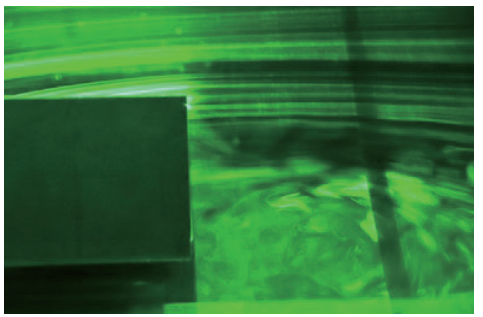

(b)

Fig. 12. (Color online) Flow visualization phenomena of airflow speed of $0.5 \mathrm{~m} / \mathrm{s}$. (a) Thermal flow field for streamline. (b) Heat dissipation module circulating eddy current at tail end.

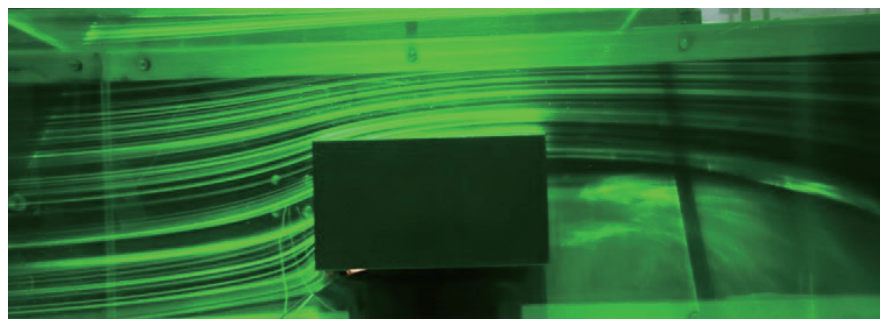

(a)

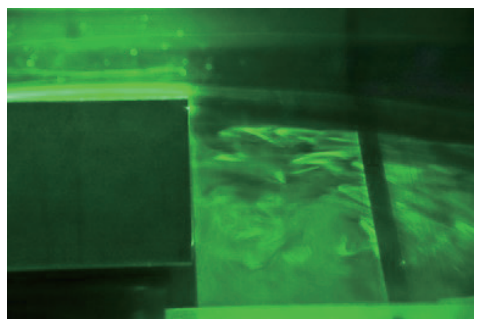

(b)

Fig. 13. (Color online) Flow visualization phenomena of airflow speed of $1.0 \mathrm{~m} / \mathrm{s}$. (a) Thermal flow field for streamline. (b) Heat dissipation module circulating eddy current at tail end. 
decreases because of the higher airflow speed, and the circulating eddy current retention area also lengthens. Also, as shown in Fig. 13(b), the smoke in the circulating vortex detention area is still squeezed by the flow field. Although the backflow of smoke causes some interference on the heat dissipation capacity, the backflow of hot air decreases and the effect on the heat dissipation module gradually decreases owing to the lengthening of the circulating eddy current retention area.

\subsubsection{Airflow speed of $1.5 \mathrm{~m} / \mathrm{s}$}

The results obtained under air convection with the airflow speed of $1.5 \mathrm{~m} / \mathrm{s}$ are shown in Fig. 14(a). Compared with the case of airflow speed of $1.0 \mathrm{~m} / \mathrm{s}$, the effect of thermal buoyancy decreases because of the higher airflow speed, and the circulating eddy current retention area gradually disappears. As shown in Fig. 14(b), the airflow is still turbulent. Compared with when the airflow speed is $1.0 \mathrm{~m} / \mathrm{s}$, the amount of smoke that returns to the recirculation vortex retention area decreases, that is, less hot air returns, and the heat gradually dissipates from the heat dissipation module area.

\subsubsection{Airflow speed of $2.0 \mathrm{~m} / \mathrm{s}$}

The results obtained under air convection with the airflow speed of $2.0 \mathrm{~m} / \mathrm{s}$ are shown in Fig. 15(a). Compared with the case of airflow speed of $1.5 \mathrm{~m} / \mathrm{s}$, the effect of thermal buoyancy gradually disappears owing to the higher airflow speed and the circulating vortex detention zone is not obvious. As shown in Fig. 15(b), the state of flow is relatively smooth. Compared with when the airflow speed is $1.5 \mathrm{~m} / \mathrm{s}$, the circulating vortex flow retention zone also gradually dissipates, such that the hot air reflux decreases and the amount of heat that can be removed by the heat dissipation module gradually increases.

\subsubsection{Airflow speed of $2.5 \mathrm{~m} / \mathrm{s}$}

The results obtained under air convection with the airflow speed of $2.5 \mathrm{~m} / \mathrm{s}$ are shown in Fig. 16(a). Compared with the case of airflow speed of $2.0 \mathrm{~m} / \mathrm{s}$, the effect of thermal buoyancy

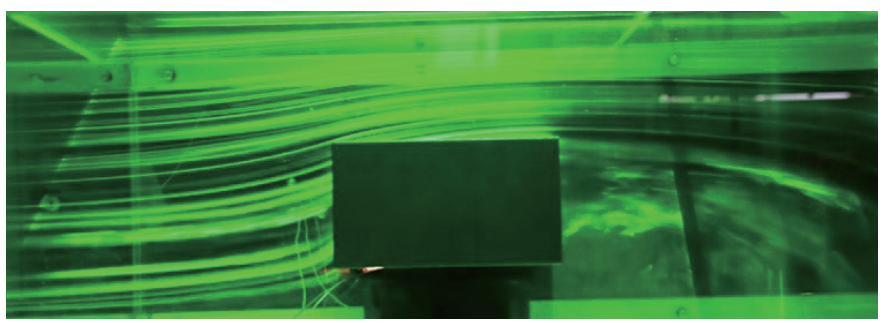

(a)

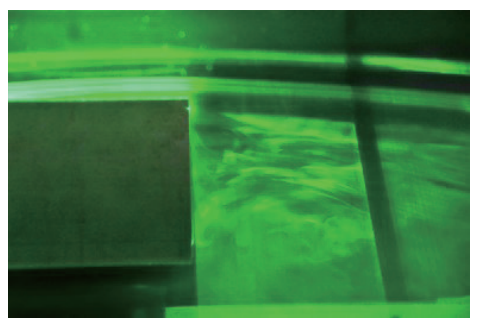

(b)

Fig. 14. (Color online) Flow visualization phenomena of airflow speed of $1.5 \mathrm{~m} / \mathrm{s}$. (a) Thermal flow field for streamline. (b) Heat dissipation module circulating eddy current at tail end. 


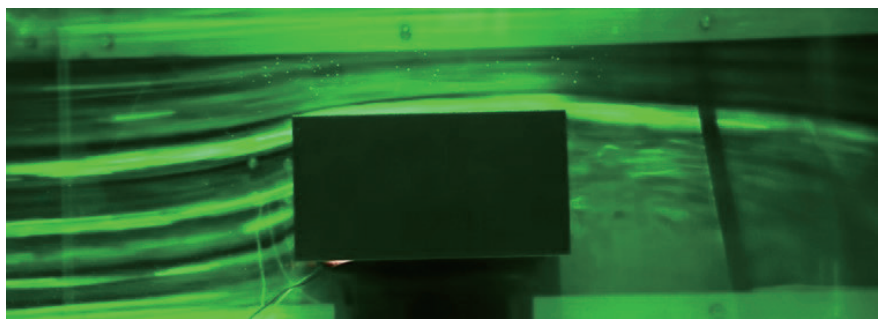

(a)

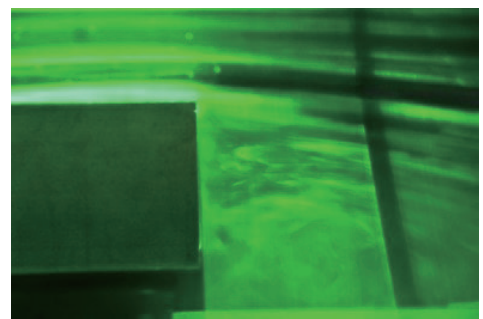

(b)

Fig. 15. (Color online) Flow visualization phenomena of airflow speed of $2.0 \mathrm{~m} / \mathrm{s}$. (a) Thermal flow field for streamline. (b) Heat dissipation module circulating eddy current at tail end.

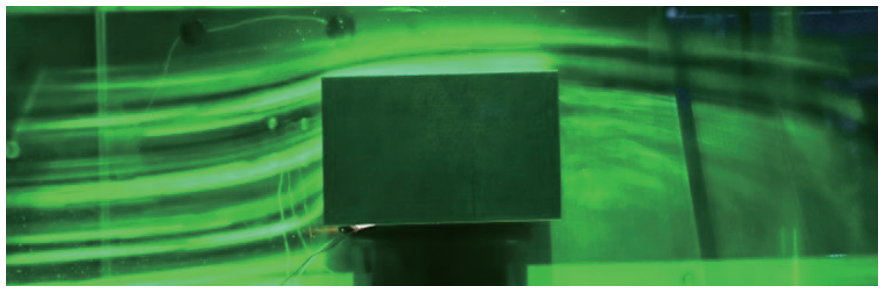

(a)

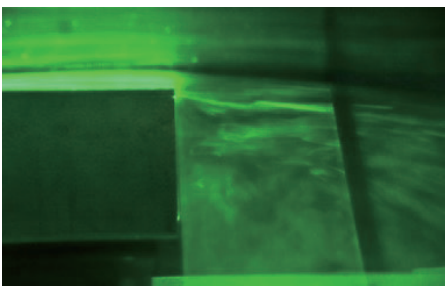

(b)

Fig. 16. (Color online) Flow visualization phenomena of airflow speed of $2.5 \mathrm{~m} / \mathrm{s}$. (a) Thermal flow field for streamline. (b) Heat dissipation module circulating eddy current at tail end.

gradually disappears because of the higher airflow speed and the circulating vortex detention zone is not very chaotic. As shown in Fig. 16(b), the state of flow is relatively smooth. Compared with when the airflow speed is $2.0 \mathrm{~m} / \mathrm{s}$, the return of smoke to the circulating vortex retention zone is negligible, which means that less hot air returns and the amount of heat that can be removed by the heat dissipation module gradually increases.

\subsubsection{Airflow speed of $3.0 \mathrm{~m} / \mathrm{s}$}

The results obtained under air convection with the airflow speed of $3.0 \mathrm{~m} / \mathrm{s}$ are shown in Fig. 17(a). Compared with the case of airflow speed of $2.5 \mathrm{~m} / \mathrm{s}$, the smoke at the rear end disappears because of the higher airflow speed and there is no chaotic disturbance in the circulating vortex detention area. As shown in Fig. 17(b), the smoke and state of flow are relatively smooth. Compared with when the airflow speed is $2.5 \mathrm{~m} / \mathrm{s}$, the recirculation of smoke in the circulating vortex retention zone almost disappears and the hot air reflux is negligible. The heat removal capacity of the cooling module greatly improves.

The flow visualization phenomena shown in Figs. 12-17 reveal that with increasing airflow speed, the thermal boundary layer between the cooling fins gradually deteriorates. Under low airflow speed, the thermal boundary layer is not easily damaged, resulting in the fluid being unable to pass through the fins smoothly and thus affecting the heat dissipation effect. When the airflow speed gradually increases, the air pressure gradually crushes the thermal boundary layer, so that the cold air can be closer to the surface of the heat sink fin, effectively accelerating 


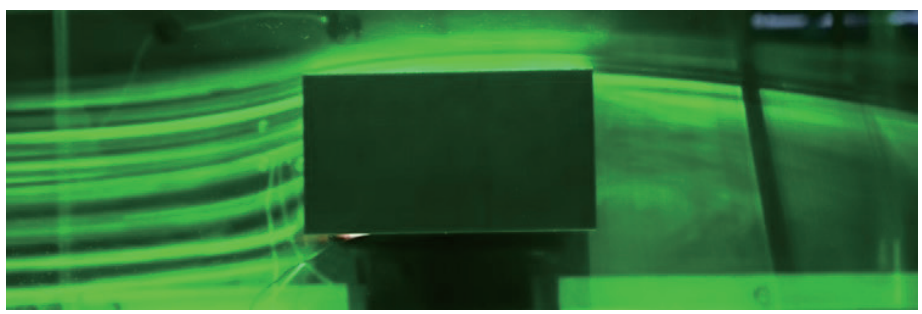

(a)

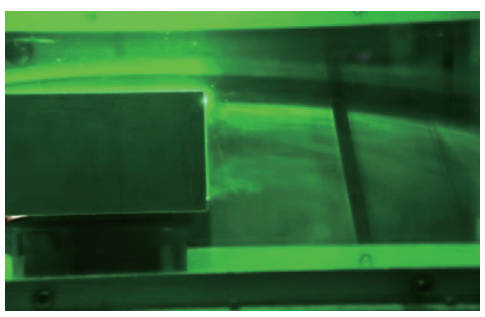

(b)

Fig. 17. (Color online) Flow visualization phenomena of airflow speed of $3.0 \mathrm{~m} / \mathrm{s}$. (a) Thermal flow field for streamline. (b) Heat dissipation module circulating eddy current at tail end.

the removal of heat. The circulation eddy current retention zone gradually dissipates the eddy current and little reflux occurs, which greatly improves the heat removal ability of the heat dissipation module.

\subsection{Infrared thermal imager temperature measurement}

The temperature distributions obtained under different airflow speeds are examined. When the airflow speeds are $0.5,1.0,1.5,2.0,2.5$, and $3.0 \mathrm{~m} / \mathrm{s}$, the infrared thermal image shows the maximum temperature, measured $T_{f}\left(T_{\text {heat sink fin }}\right)$, and emissivity $\varepsilon$, which are indicated in Table 1.

Figures 18-23 show infrared thermal images that indicate the temperature distribution of cooling fins at different airflow speeds. The temperature at the heating position of the $\mathrm{COB}$ LED substrate is the highest, and heat is transmitted to the heat dissipation fin module. In each side view, it can be seen that at a lower airflow speed, the high-temperature distribution area (red) is larger. With increasing airflow speed, the red area gradually decreases, indicating that heat is removed smoothly under high airflow speeds. The actual measurement position is at the center of the middle fin module, the continuing study of which is valuable and of physical significance.

\subsection{Luminance}

The COB LED is placed in an environmental control room and $T_{\text {case }}$ is controlled by forced convection cooling $(1.5-1.7 \mathrm{~m} / \mathrm{s})$. The improvement in luminance caused by heat dissipation is observed. The changes in voltage and current are recorded and the change in luminous efficiency is analyzed. The illumination is measured with a spectrophotometer. As shown in Fig. 24, $T_{\text {case }}$ is $58^{\circ} \mathrm{C}, T_{j}$ is $92{ }^{\circ} \mathrm{C}$, the illumination is 9626 lux, the color temperature is $3261 \mathrm{~K}$, the color rendering property is 82 , the spectral peak is at $601 \mathrm{~nm}$, and the input power is 101.4 $\mathrm{W}$ at the ambient temperature $\left(T_{a}\right)$ of $25^{\circ} \mathrm{C}$. The input power is $100 \mathrm{~W}$ when $T_{\text {case }}$ is $50 \pm 5{ }^{\circ} \mathrm{C}$. The temperature of the environmental control room gradually decreases from 25 to $20,15,10$, 5,0 , and $-5^{\circ} \mathrm{C}$. The voltage, current, illuminance, power, $T_{\text {case }}$, and $T_{j}$ are recorded every $5{ }^{\circ} \mathrm{C}$ decrease in temperature. As shown in Fig. $25, T_{\text {case }}$ is $36{ }^{\circ} \mathrm{C}, T_{j}$ is $86{ }^{\circ} \mathrm{C}$, the illumination is 10433 lux, the color temperature is $3272 \mathrm{~K}$, the color rendering property is 82 , the spectral peak is at $601 \mathrm{~nm}$, and the input power is $97.4 \mathrm{~W}$ at $T_{a}$ of $-5{ }^{\circ} \mathrm{C}$. The results show that the overall 
Table 1

Temperature distributions obtained under different airflow speeds.

\begin{tabular}{lccc}
\hline Airflow speed & Maximum temperature & $T_{f}\left(T_{\text {heat sink fin }}\right)$ & Emissivity $\varepsilon$ \\
\hline $0.5 \mathrm{~m} / \mathrm{s}$ & $51.0-52.9^{\circ} \mathrm{C}$ & $45.78^{\circ} \mathrm{C}$ & 0.95 \\
$1.0 \mathrm{~m} / \mathrm{s}$ & $48.2-50.1^{\circ} \mathrm{C}$ & $42.16^{\circ} \mathrm{C}$ & 0.95 \\
$1.5 \mathrm{~m} / \mathrm{s}$ & $46.1-48.4^{\circ} \mathrm{C}$ & $40.2{ }^{\circ} \mathrm{C}$ & 0.95 \\
$2.0 \mathrm{~m} / \mathrm{s}$ & $43.9-46.1^{\circ} \mathrm{C}$ & $37.80^{\circ} \mathrm{C}$ & 0.95 \\
$2.5 \mathrm{~m} / \mathrm{s}$ & $42.0-43.3^{\circ} \mathrm{C}$ & $35.61{ }^{\circ} \mathrm{C}$ & 0.95 \\
$3.0 \mathrm{~m} / \mathrm{s}$ & $40.7-41.7^{\circ} \mathrm{C}$ & $33.34{ }^{\circ} \mathrm{C}$ & 0.95 \\
\hline
\end{tabular}

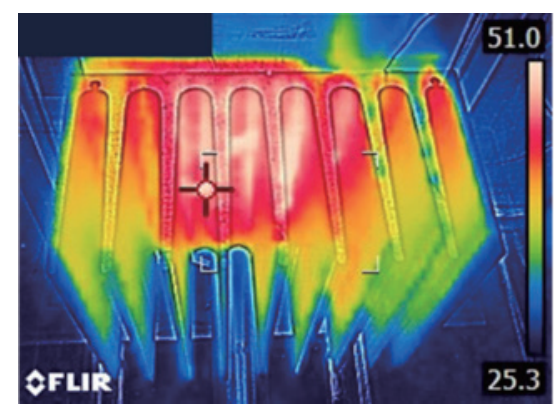

(a)

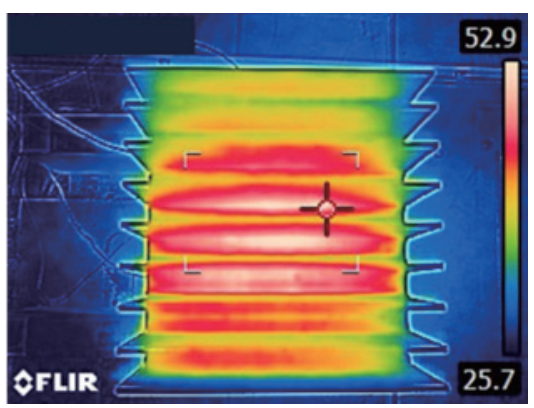

(b)

Fig. 18. (Color online) Temperature distribution of heat sink fin when airflow speed is $0.5 \mathrm{~m} / \mathrm{s}$. (a) Side view. (b) Top view.

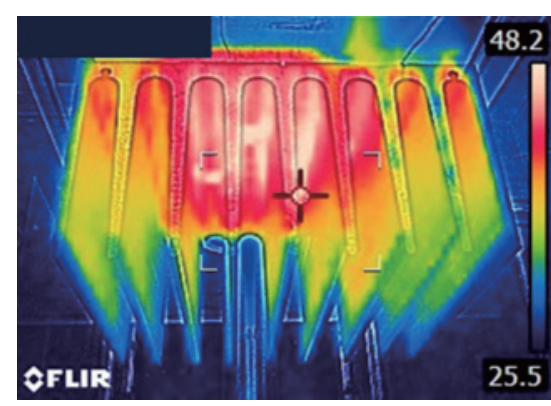

(a)

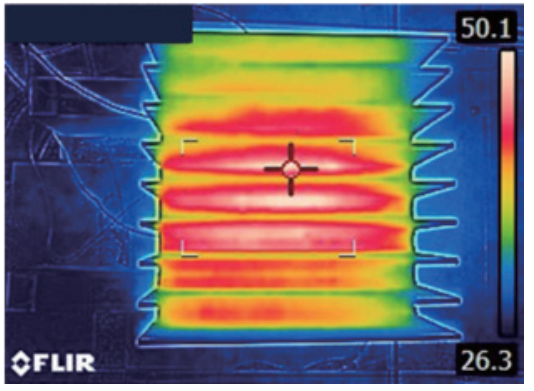

(b)

Fig. 19. (Color online) Temperature distribution of heat sink fin when airflow speed is $1.0 \mathrm{~m} / \mathrm{s}$. (a) Side view. (b) Top view.

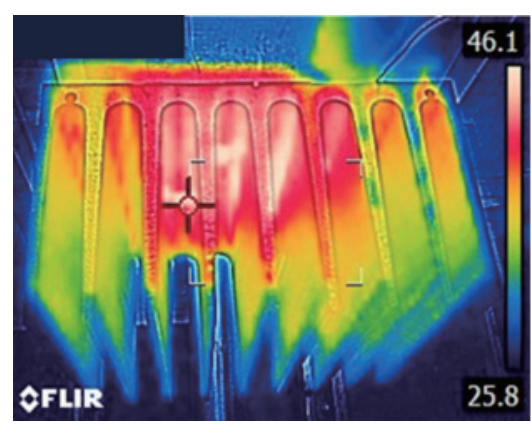

(a)

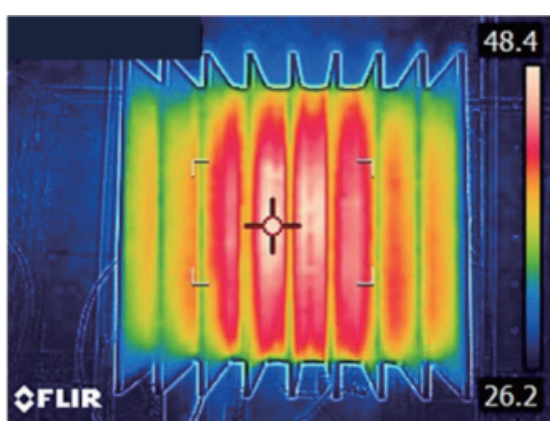

(b)

Fig. 20. (Color online) Temperature distribution of heat sink fin when airflow speed is $1.5 \mathrm{~m} / \mathrm{s}$. (a) Side view. (b) Top view. 


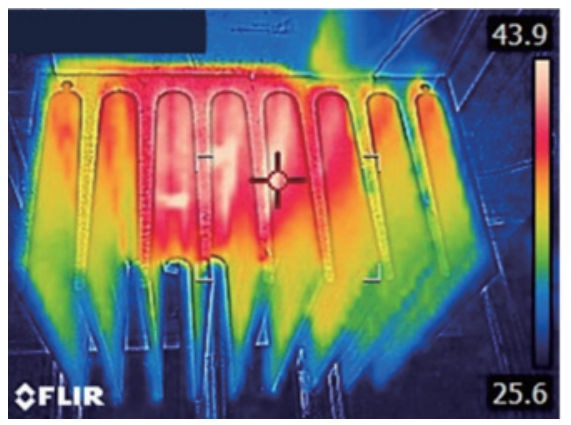

(a)

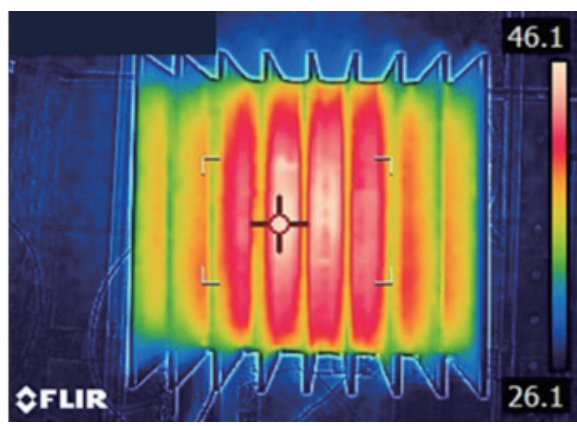

(b)

Fig. 21. (Color online) Temperature distribution of heat sink fin when airflow speed is $2.0 \mathrm{~m} / \mathrm{s}$. (a) Side view. (b) Top view.

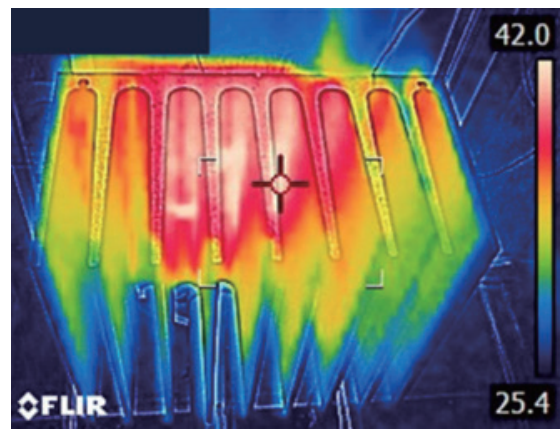

(a)

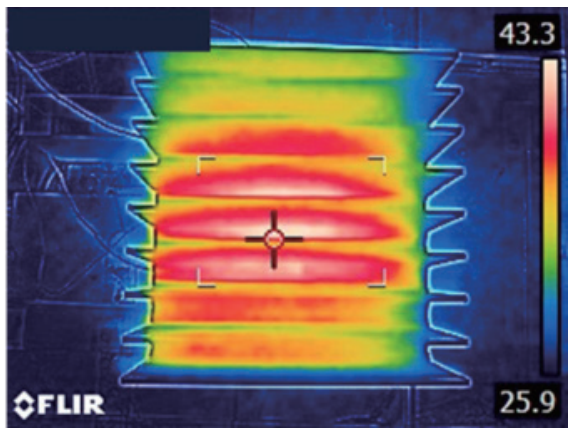

(b)

Fig. 22. (Color online) Temperature distribution of heat sink fin when airflow speed is $2.5 \mathrm{~m} / \mathrm{s}$. (a) Side view. (b) Top view.

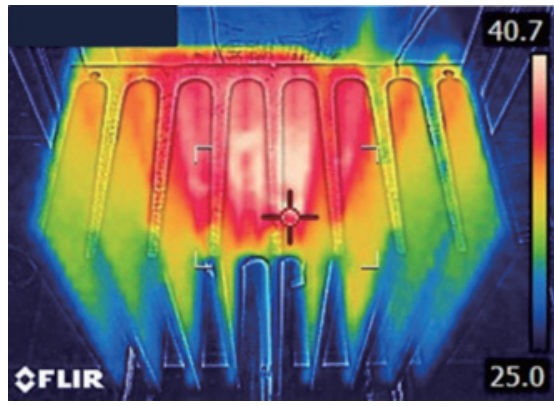

(a)

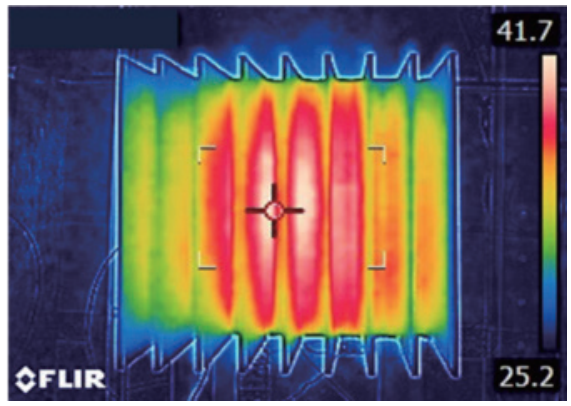

(b)

Fig. 23. (Color online) Temperature distribution of heat sink fin when airflow speed is $3.0 \mathrm{~m} / \mathrm{s}$. (a) Side view. (b) Top view.

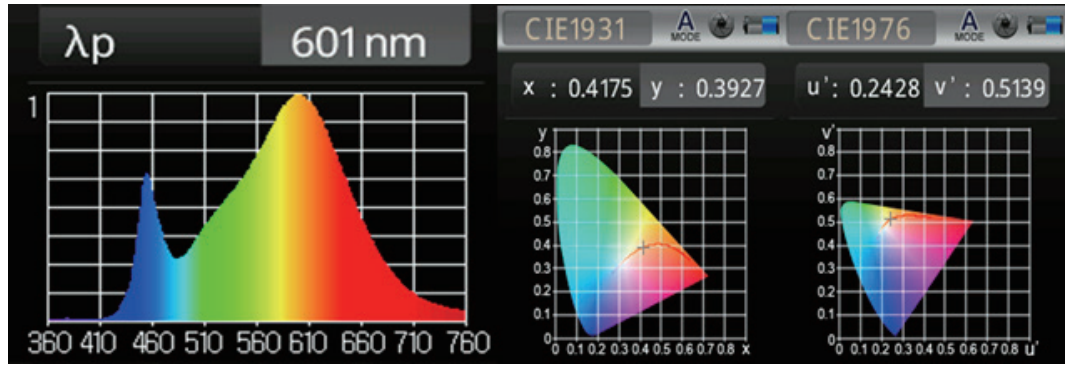

Fig. 24. (Color online) Illumination of COB LED is 9626 lux at $T_{a}$ of $25^{\circ} \mathrm{C}$. 


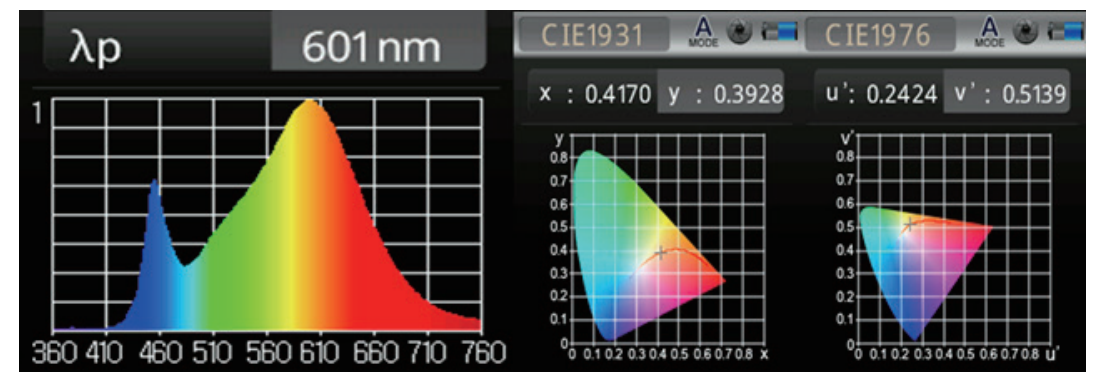

Fig. 25. (Color online) Illumination of COB LED is 10433 lux at $T_{a}$ of $-5^{\circ} \mathrm{C}$.

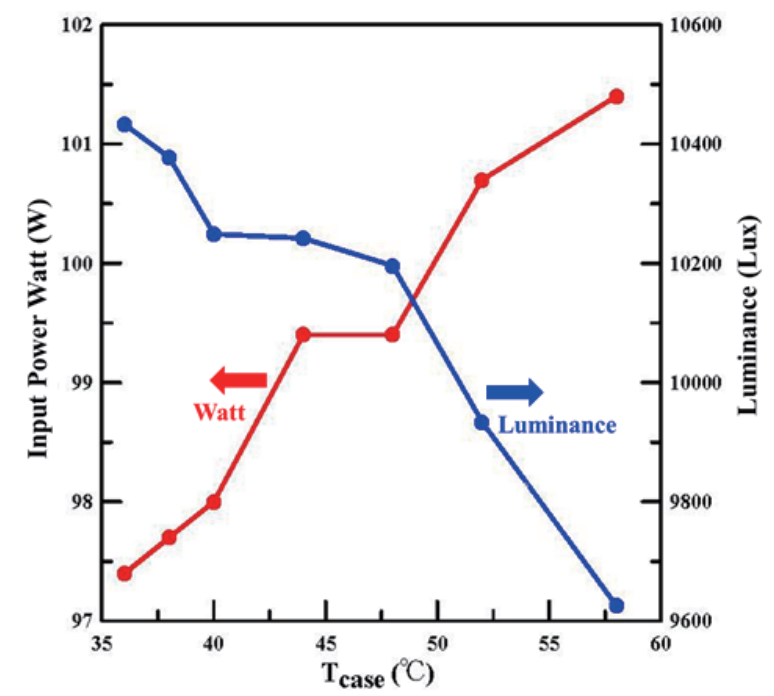

Fig. 26. (Color online) Changes in $T_{\text {case }}$, luminance, and input power.

efficiency of COB LED illumination is improved by $8.3 \%$, and $4.0 \%$ of input power is saved. The overall efficiency of the COB LED is significantly improved, and the change in $T_{\text {case }}$ with illumination and input power can be seen in Fig. 26.

\section{Conclusions}

The design of the COB LED light-emitting module adopted in this study is the mainstream in multichip solid-state lighting. The use of convection heat dissipation is needed to strengthen the customized heat transfer mode. The use of an interface thermally conductive material is also important. Moreover, graphene has become the development option of the new generation of thermal conduction materials. Its heat conduction capacity is good and it is easy to deploy. The development of thermal graphene grease materials has been highly successful, and they will be widely used as thermal conduction interface materials in the future, mainly because if $T_{\text {case }}$ can be decreased, the power consumption of the LED module will decrease and its luminous lighting will increase, which means that the overall luminous efficiency will be improved with the improvement in heat dissipation capacity. For convection with low airflow speed, the larger the temperature difference, the less heat energy will be taken away. If the 
temperature difference is small, much heat energy will be taken away. Between 0.5 and $1.0 \mathrm{~m} / \mathrm{s}$, the difference in $T_{\text {case }}$ is $4.2{ }^{\circ} \mathrm{C}$. Between 2.5 and $3.0 \mathrm{~m} / \mathrm{s}$, the difference in $T_{\text {case }}$ is $2.6^{\circ} \mathrm{C}$. The high-speed convection helps to reduce $T_{j}$, and the temperature easily reaches stability quickly. The measured data are obtained by thermocouple temperature sensing and airflow speed sensing under steady state. However, when the air convection wind speed reaches a certain level, the heat dissipation capacity decreases because the shorter the stay time of the air-cooled molecules on the surface of the fin, the less effective is the heat exchange and, therefore, heat energy cannot be reduced and the load and energy consumption increase. Furthermore, it is found that the surface of the heat sink fin is affected by the buoyancy of high-temperature air, resulting in a greater thermal boundary layer thickness when the temperature is high. As the temperature increases, the thermal boundary layer thickens, resulting in smaller gaps between the cooling fins. High-speed convection cannot destroy the thermal boundary layer owing to the wind pressure, but a retention area is formed at the tail end of the heat sink fin. The heat dissipation capacity is reduced by backflow around the fin, and the flow rate increases when such backflow occurs. Therefore, the development of the COB LED thermal conduction interface graphene grease material is important, and it is also necessary to introduce and strengthen material configurations in a timely manner.

\section{Acknowledgments}

We would like to thank the Ministry of Science and Technology of Taiwan of the Republic of China for financially supporting this research under contract numbers MOST 104-2221-E-167-015, MOST 104-ET-E-167-001-ET, and MOST 108-2221-E-167-005-MY2, and Associate Professor Dr. C. W. Lu (NCUT) for his assistance with the infrared thermal imager measurement equipment for measuring the thermal fluid temperature distribution. We would also like to thank Long Win Corp., Ltd. for the rental of the air wind channel (tunnel) equipment for testing thermal flow. We have paid a fee to use the air wind channel equipment and study and discuss some results.

\section{References}

1 LED - Light-emitting diode. USA, https://zh.wikipedia.org/wiki/LED (accessed February 2020).

2 High - Intensity Discharge - HID. USA, https://zh.wikipedia.org/wiki/HID (accessed March 2020).

3 Semiconductor Devices: Pioneering Papers. Singapore, https://www.worldscientific.com/doi/ abs/10.1142/9789814503464_0116 (accessed March 2020).

4 J. Damery: Holonyak Retires after 50 Years in ECE. University of Illinois. USA, https://ece.illinois.edu/ newsroom/news/3121 (accessed April 2020).

5 S. Gustavsson: Blue LEDs - Filling the world with new light. The Nobel Prize in Physics 2014-Popular Science Background. Nobel Prize (2014): The Royal Swedish Academy of Sciences. Kungl. Vetenskaps - Akademien. Sweden, https:/www.nobelprize.org/prizes/physics/2014/summary (accessed May 2020).

6 Y. C. Huang: The Improvement of Luminous Efficiency and Thermal Spreading Using Aluminum Nitride Ceramic Substrate of LED Module, MS. Thesis, Dept. of Mech. Eng. (CYCU, Taoyuan, Taiwan, 2017).

7 M. Arik, J. Petroski, and S. Weaver: 8th Intersociety Conf. Thermal and Thermomechanical Phenomena in Electronic Systems (ITherm, IEEE, 2002) 113-120. https://doi.org/10.1109/ITHERM.2002.1012446.

8 C. W. Wang: The Study on the Fabrication of Gaphene Thermal Compound, MS. Thesis, Dept. of Mech. Eng. (Tungnan University, New Taipei, Taiwan, 2014). 
9 H. H. Wu, K. H. Lin, and S. T. Lin: J. Tech. 27 (2012) 73. https://doi.org/10.29507/JT.201206.0003

10 Y. L. Yu: Heat Transfer Analysis of High-Power LED Bulb Thermal Module Using High Thermal Conductivity Plastic, MS. Thesis, Dept. Eng. Sci. (NCKU, Tainan, Taiwan, 2014).

11 F. Ren, Y. Yin, Y. Wang, Z. Liu, M. Liang, H. Ou, J. Ao, T. Wei, J. Yan, G. Yuan, X. Yi, J. Wang, J. Li, D. Dasa, and H. Weman: Materials 11 (2018) 2372. https://doi.org/10.3390/ma11122372

12 M. W. Jeong, S. W. Jeon, and Y. C. Kim: Appl. Therm. Eng. 91 (2015) 105. https://doi.org/10.1016/ j.applthermaleng.2015.08.001

13 Y. C. Yang: Investigation on Heat Transfer in Parametric Design of LED Energy Saving Cup Lamp Heat Fins, M.S. Thesis, Dept. of Industrial Edu. (NTNU, Taipei, Taiwan, 2017).

14 W. S. Jhou: Thermal Analysis for High Power Multi-Chip COB LED with a Heat Sink, M.S. Thesis, Dept. Electro-Opical Eng. (KSU, Tainan, Taiwan, 2016).

15 J. J. Wu: Simulation Study of High Power LED Cooling, MS. Thesis, Dept. Mech. and Computer-Aided Eng. (St. John's University, New Taipei, Taiwan, 2015).

16 K. B. Abdelmlek, Z. Araoud, K. Charrada, and G. Zissis: Appl. Therm. Eng. 126 (2017) 653. https://doi. org/10.1016/j.applthermaleng.2017.07.136

17 C. Xiao, H. Liao, Y. Wang, J. Li, and W. Zhu: Appl. Therm. Eng. 111 (2017) 1320. https://doi.org/10.1016/ j.applthermaleng.2016.10.041

18 C. N. Hsu and C. C. Huang: Int. J. Green Energy 13 (2016) 1026. https://doi.org/10.1080/15435075.2016.120600 3

19 C. N. Hsu, W. C. Wang, and S. H. Fang: J. Therm. Analy. Calori. 136 (2019) 2097. https://doi.org/10.1007/ s10973-018-7806-6

20 X. Lin, S. Mo, B. Mo, L. Jia, Y. Chen, and Z. Cheng: Appl. Therm. Eng. 172 (2020) 115165. https://doi. org/10.1016/j.applthermaleng.2020.115165

21 C. C. Huang: A Study on Heat Transfer of Air-conditioning System Bypass Cooling Multi-chip Light Emitting Diode, M.S. Thesis, Dept. Refrigeration, Air Conditioning and Energy Eng. (NCUT, Taichung, Taiwan, 2013).

22 S. H. Fang: LED Cooling on a Cold Plate Using a Refrigeration Cycle, M.S. Thesis, Dept. Refrigeration, Air Conditioning and Energy Eng. (NCUT, Taichung, Taiwan, 2016).

23 C. H. Chang: Thermal Fluid Experimental and Computational Analysis of Light Emitting Diode at a level of 100W, MS. Thesis, Dept. Refrigeration, Air Conditioning and Energy Eng. (NCUT, Taichung, Taiwan, 2016).

24 C. C. Chen: Thermal Fluid Experiments for Ultra-High Power COB LED Graphene Heat Dissipation, M.S. Thesis, Dept. Refrigeration, Air Conditioning and Energy Eng. (NCUT, Taichung, Taiwan, 2018).

25 S. Lee, J. Y. Hong, and J. Jang: ACS Nano. 7 (2013) 7. https://doi.org/10.1021/nn4024587

\section{About the Authors}

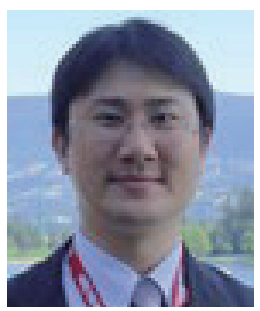

Chih-Neng Hsu received his M.S. and Ph.D. degrees from National Tsing Hua University, Taiwan, R.O.C., in 2000 and 2005, respectively. From 2011 to 2015, he was an assistant professor at National Chin-Yi University of Technology, Taiwan, R.O.C. Since 2015, he has been an associate professor at National Chin-Yi University of Technology, Taiwan, R.O.C. His research interests are in refrigeration and air conditioning, LED/laser diodes, thermal fluid science, energy engineering, lighting, electronic cooling, CFD/CAD/ $\mathrm{CAE}$, measurement, IAQ, energy saving, and graphene materials. (cnhsu@ncut.edu.tw)

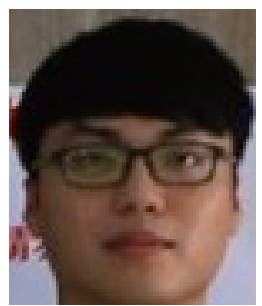

Chun-Chih Chen received his B.S. and M.S. degrees from National ChinYi University of Technology, Taiwan, in 2016 and 2018, respectively. His research interests are in refrigeration and air conditioning, LED, measurement, and thermal fluid. (zeluc8657@gmail.com) 


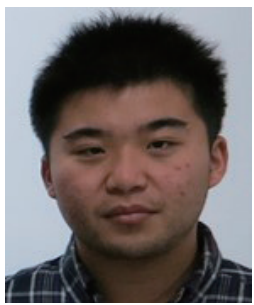

Chen-Hui Chang received his B.S. and M.S. degrees from National ChinYi University of Technology, Taiwan, in 2014 and 2016, respectively. His research interests are in refrigeration and air conditioning, LED, thermal fluid, CFD, CAD, measurement, and graphene materials.

(destinygundam005@yahoo.com.tw)

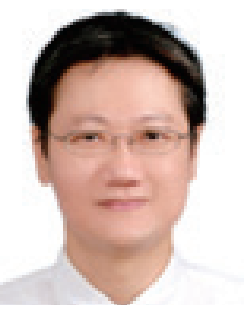

Cheng-Chi Wang received his B.S., M.S., and Ph.D. degrees from the Department of Mechanical Engineering, National Cheng Kung University, Tainan, Taiwan, in 1996, 1998, and 2001, respectively. Now, he serves as a distinguished professor in the Graduate Institute of Precision Manufacturing of National Chin-Yi University of Technology in Taiwan. His current research involves intelligent machining and manufacturing, nonlinear dynamic analysis, simulation and optimization, air lubrication systems, and signal processing. (wcc@ncut.edu.tw) 